\title{
Study on the Cracks in Pressure Pipes of Boiler Pressure Vessels
}

\author{
Xuanming Feng \\ Lvliang Special Equipment Supervision and Inspection Institute, Lvliang, Shanxi, 033000, China
}

Keywords: Pressure Pipe, Boiler Pressure Vessels, Detection and Inspection.

\begin{abstract}
Boilers are widely used in China. The working principle is that after the fuel burns, it releases huge amounts of steam and uses steam to perform various tasks. Then, the safety of boiler and pressure vessel pipelines is very important. The safety of pipelines is closely linked to the safety of people's lives and property. In daily life, cracks often occur in boilers. Cracks are one of the most harmful defects of boiler pressure vessel pipes. Therefore, we must pay attention to the inspection of boiler and pressure vessel piping. This article simply analyses the cracks often appearing in boiler pressure vessel pipes and proposes some solutions.
\end{abstract}

\section{Introduction}

Boiler pressure vessel pressure piping has been in a high temperature and high pressure operating environment for a long time. If there is a crack in the equipment, it will increase the probability of equipment explosion, which will not only cause serious economic losses to the enterprise, but also threaten the life safety of workers. Therefore, in order to ensure the safe and stable production of the enterprise, the managers and operators of the enterprise need to fully realize the importance of crack detection work of the boiler pressure vessel pressure pipe, analyse the common crack problems of the boiler pressure vessel pressure pipe, and adopt scientific and effective Measures to reduce the possibility of cracks in the pressure pipes of the boiler pressure vessel as much as possible.

\section{3 common crack problems}

At present, there is no unified classification standard for cracks appearing in pressure pipes of boiler pressure vessels. This article classifies cracks based on the basic principles of crack formation and propagation.

The main types are as follows:

(1) Stress corrosion cracking. This type of crack is mainly formed by the combined action of stress and corrosives. Container sockets and soda pipes in boilers are the key areas where stress corrosion cracking occurs. The appearance of this crack is usually vertical, and dendritic cracks are usually formed on austenitic fittings. Stress corrosion in boilers of thermal power plants generally occurs on the inner walls of pressure vessels and pressure pipes. Such cracks can also be called stress-induced corrosion cracks. Creep caused by creep damage, Creep damage is caused by the phenomenon of material separation caused by long-term operation of the boiler. Generally, under the combined effect of stress and temperature, deformation and metal damage occur, and cracks appear. This creep crack is perpendicular to the direction of the maximum stress, and it often appears in the high stress strain zone of the header and pipeline, especially the welds of the header of the header, the edge area of the high-temperature component, the hole bridge area, the bend of the high-temperature pipeline, and other areas. When creep damage is severe, elliptical and granular holes appear irregularly throughout the metal, and these holes are connected to produce cracks. Stress corrosion cracking Stress corrosion cracking is caused by corrosion. For example, a large concentration of alkaline water is the main reason for the corrosion of pressure pipes in boiler pressure vessels. Corrosivity creates a potential difference between the metal crystals, which can form the anode and cathode, and then form a small current. These small currents are highly corrosive, causing cracks in the metal to develop from the crystal interface to the deep surface. This 
kind of crack causes corrosion, which generally develops from the inside to the outside, and is usually distributed in locations with high stress. Corrosion fatigue cracks Corrosion fatigue cracks are the result of the combined action of corrosive materials and stress fatigue. Most of these cracks are generated in groups and penetrate through crystals. The corrosion fatigue crack will become wider and wider with time. The crack is full of corrosive substances, and the inner wall of the pipe is filled with corrosive grooves, channels and pits. If the crack continues to develop, the branch ends of the crack will be compared. slow. Corrosion cracks are the basis for fatigue of pressure pipes of boiler pressure vessels and are also affected by corrosive substances. Therefore, after the fatigue cracks occur, the boiler equipment is continuously used to cause corrosive cracks. According to the nature of corrosive cracks and mechanical fatigue cracks, these two crack phases are similar. They are basically boiler equipment in use, and its main pressure components cannot function. In addition, the locations where cracks occur have specific regularity and specificity, and are not random.

(2) Mechanical crack. This type of crack mainly occurs on the auxiliary rotating equipment, impellers and large shafts of the boiler, and is usually concentrated at the intersection of multiple surfaces of the boiler. Mechanical cracks are relatively short in the initial formation stage, and then continue to extend inward in the form of tunnels, and form a long crack with time, and finally expand at a stable speed. Usually, in the initial formation stage of the lower mechanical crack, the crack and the direction of the stress are generally distributed at an angle of 45 degrees. With the extension of time, cracks continue to accelerate, and at this time the cracks are distributed at 90 degrees to the mechanical stress. Mechanical fatigue cracks Mechanical fatigue cracks generally occur in turbine impellers, blades, large shafts, and rotating machinery and equipment. Such cracks generally occur in areas with relatively concentrated strain, and most of them diffuse from the surface of the component. The crack growth is directly related to the material structure, stress conditions, environment, and time. There is no obvious deformation at the beginning of the crack. Usually, the crack is penetrating. The crack is very curved and perpendicular to the main stress. Development can also see the crack again. Mechanical fatigue cracks are linear in shape. At the beginning, the cracks are not large and slowly develop inward. The crack openings are relatively wide, and there are many plaques. The ends are sharp. The two sides of the crack are relatively neat and very thick. shallow. The shape of the mechanical fatigue crack is not obvious at the beginning, and the shape becomes more obvious as the time goes by. However, the early concealment of the crack is good and it is not easy to find.

(3) Creep crack. This type of crack has a lot to do with the service life of the pressure vessel and pressure pipe of the boiler. During the actual use of the boiler, the interaction between stress and temperature will damage the metal structure, resulting in the occurrence of creep cracks. From the position of the main crack, it is perpendicular to the main stress in the pressure vessel pressure pipe. It generally extends along the axis at the location of the curve. In a large area of cracks, there are usually several parallel cracks around the main grain at the same time.Cracks caused by overheating and overheating are made from fixed metal plates through rolling, welding and other processes to make boiler pressure vessels. During the process of manufacturing boilers, the boiler is prone to cracks. Because the temperature is too high during the production process, overheating, overheating will cause cracks. Overheating and overheating generally occur during the hot working process of load-bearing components, such as forging and bending. Overheating is caused by the metal heating temperature exceeding the critical point and continued heating; Overheating is the temperature of the heated metal is relatively high, due to local melting and cracks caused by oxidation of the crystal. Overburned metal cannot withstand the test of deformation, and cracks in the process of forging and rolling leave hidden dangers to load-bearing components. If the temperature is too high, thermal cracks will occur, and if the temperature is too low, cracks will also occur.

\section{Effective strategies for preventing cracks in pressure pipes of boiler pressure vessels}

Inspection of equipment, parts and raw materials is essential. By strengthening the inspection of equipment, parts and raw materials to ensure that the quality and specifications of equipment, parts 
and raw materials meet actual needs, this reduces the probability of cracks in the pressure pipes of boiler pressure vessels, and ensures the safety of production and people's lives. In the process of making boiler pressure vessels and pressure pipes, it needs to be carried out according to relevant quality inspection requirements and standards. The inspection objects mainly include pressure pipeline products and raw materials. The quality of raw materials directly affects the quality of pressure pipes of boiler pressure vessels. Therefore, we must do a good job of quality inspection of raw materials. After ensuring that the quality of the raw materials meets the relevant requirements, the quality inspection of the parts is performed. Every small part has an error or quality problem, which will affect the quality of the boiler pressure vessel pressure pipe. [Therefore, during processing and manufacturing parts, we must use the most suitable manufacturing process and strictly follow the relevant operating specifications to ensure that all production steps can be carried out in strict accordance with the production standards, ensuring the quality of all parts.] Lay a solid foundation for quality and operational safety. When performing equipment quality inspection, it is necessary to inspect the operating quality of the equipment to ensure that the equipment can operate normally and avoid cracks. In addition, during the boiler manufacturing process, strict and comprehensive testing by a third-party agency should be conducted to find out in a timely and accurate manner whether there are irregular or unreasonable phenomena in the manufacturing process. Once hidden problems are detected, measures must be taken to deal with them in time to effectively reduce the probability of cracks in the pressure pipes of the boiler pressure vessel.

Boiler is an emerging technology to improve the performance of corrosion resistance and wear resistance as an important design improvement to convert coal resources into energy. The cladding repair applies thermal energy to the coating surface of the base metal under vacuum, and quickly melts the alloy coating pre-coated on the surface of the substrate and wets it. When condensing, the coating recrystallizes together with the miscible zone and is tightly bonded to the substrate. For cylinders with excessively large wear, you can use a special machine to ream them, and then process the cylinder liner separately. Take the hot pressing method to integrate with the original cylinder insert, and then according to the inner diameter of the cylinder liner, finish machining A new screw to ensure that it can absolutely match the inner diameter of the new cylinder liner. When the screw and barrel need to be replaced, they should be purchased from the manufacturer as much as possible to ensure that they have a good match. In order to prevent the formation of cracks, it is necessary to prevent them in advance and control the correct operation of the boiler pressure vessel. First of all, in the production of boiler pressure vessels and pressure pipes, the production process must be strictly controlled, and each operation step is carried out in accordance with national regulations. Secondly, the manufactured products must be strictly inspected to ensure that they meet the design standards. Finally, during the production and production of the boiler, the relevant staff must also strictly follow the prescribed process flow. The staff must be responsible and familiar with the entire process of operation. Do not make any mistakes and errors in the production process . The production enterprise shall clearly stipulate the procedure files of the entire process system, ensure the accuracy of the drawings and documents, and ensure that the staff can operate in full accordance with the prescribed process drawings and procedures.

\section{Conclusion}

The crack problem is a problem often encountered in the inspection of boiler pressure vessels and pressure pipes. Cracks formed for various reasons are a great safety hazard and seriously threaten people's life and property safety. Therefore, relevant departments should fully understand the causes of these cracks, and actively take effective measures to prevent them, so as to eliminate the potential safety hazards from the source and ultimately achieve safe production.

\section{References}

[1] Xiang Zhi. Cracks in Pressure Pipe Inspection of Boiler Pressure Vessel [J]. Petroleum and Chemical Equipment, 2011, 14 (10): 51-53. 
[2] Li Hongyan. Research on Cracks in Boiler Pressure Vessel and Pressure Pipe Inspection [J]. Heilongjiang Science and Technology Information, 2013 (14): 14-14.

[3] Xie Liuhao. Cracks in Pressure Pipe Inspection of Boiler and Pressure Vessel [J]. Science \& Technology Innovation and Application, 2014, 000 (023): 118-121.

[4] Li Guangbin. Research and Treatment of Cracks in Boiler Pressure Vessel and Pressure Pipe Inspection [J]. Shandong Industrial Technology, 2015 (4): 32-32.

[5] Cui Ning. Research on Cracks in Boiler Pressure Vessel and Pressure Pipe Inspection [J]. Military and Civilian Dual-Use Technology and Products, 2017 (6):12-19.

[6] Wei Xijun. Analysis of cracks in boiler and pressure vessel pressure pipeline inspection [J]. World of Digital Communications, 2017 (12):2-7. 